\title{
Professor Fakhreddin Ghavami (1930-2021); A Role Model of Professional Commitment
}

\author{
Mohammad Hossein Azizi, MD ${ }^{1 *}$; Moslem Bahadori, MD $^{2}$; Mohsen Naseri, MD $^{3}$ \\ ${ }^{1}$ Academy of Medical Sciences of the I. R. of Iran, Tehran, Iran \\ ${ }^{2}$ Tehran University of Medical Sciences, Alumni Office, Tehran, Iran \\ ${ }^{3}$ The Former Professor of Neonatology of the Bahrami's Children Hospital, Tehran University of Medical Sciences, Tehran, Iran
}

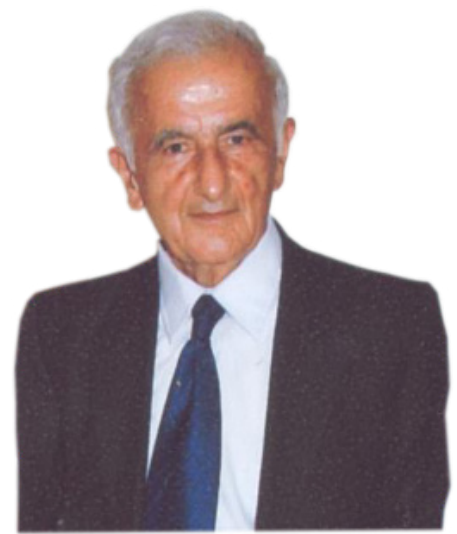

Professor Fakhreddin Ghavami (1930-2021)

Professor Fakhreddin Ghavami was an eminent pediatrician who has an exceptional position in the history of contemporary medicine in Iran as an example of professional commitment. A brief story of his life and career is presented here.

Fakhreddin Ghavami was born in an educated family on June 13, 1930 in Dezashib, Shemiran district in the northern Tehran. His father, Mr. Hassan Ghavami, was a proficient teacher. Fakhreddin completed his elementary education at the Shapur Primary School and continued his training at the Shapur and the Alborz High schools in Tehran. At that time, Dr. Mohammad Ali Mojtahedi
(1908-1997) was the Principal of Alborz High School, and Fakhreddin was one of the best students of that prestigious high school. He obtained the maximum discipline grade, based on strict criteria of Dr. Mojtahedi; an achievement that he considered as an honor in his life. He said in an interview in 2012, "When I finished high school, I was hesitant for choosing the right career path; however, I followed my father's advice and decided to study medicine." Accordingly, in 1948, he enrolled at the Medical School of Tehran University. He had 90 classmates including Reza Gharib, Moslem Bahadori and Mohammad Hassan Kariminejad, and many of his classmates later became either university professors or eminent physicians. Fakhreddin received his MD diploma in 1954 (Figures 1 and 2) and continued his post- graduate training in pediatrics at the pediatric clinic under Professor Mohammad Gharib (1909-1975); a renowned French trained professor of the Tehran School of Medicine who is known as the founder of modern pediatrics in Iran. ${ }^{2}$

In 1958, the young Dr. Ghavami became a pediatrician. The title of his medical thesis was "The Radiologic Signs in Myxedema". He started his medical practice in 1961, as the Director of Pediatric Clinic at the Bahrami’s Children Hospital in eastern Tehran. At that time, Dr. Sadegh Mokhtarzadeh (born in Tabriz, 1917) was the director of the hospital (Figure 3). In 1967; Dr. Ghavami became an associate professor of pediatrics.
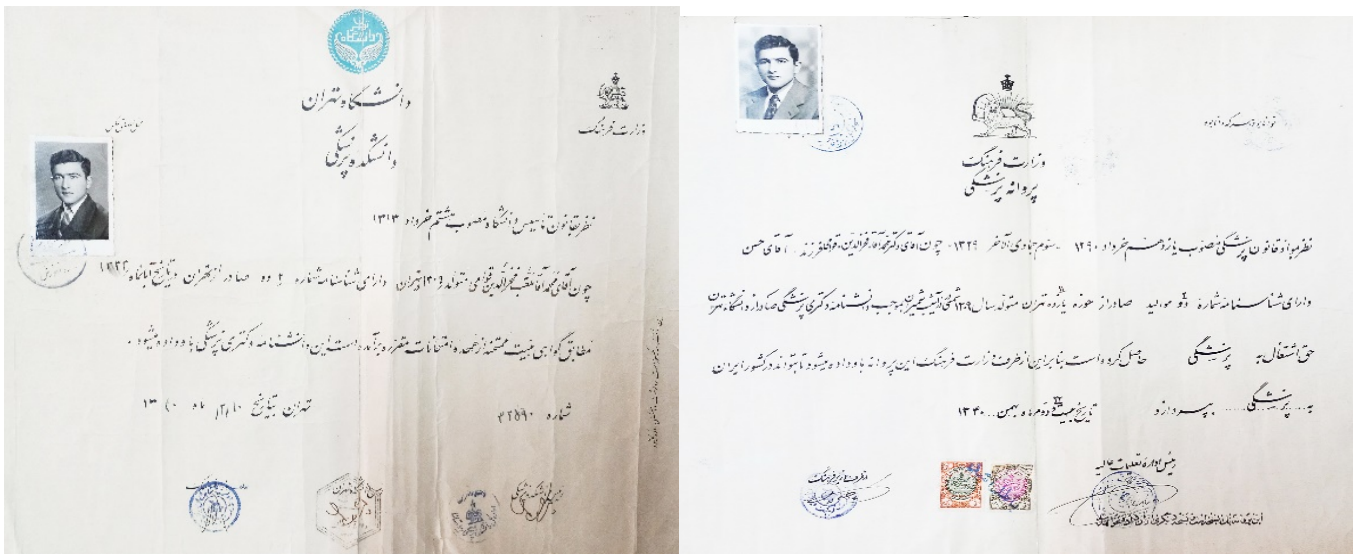

Figure 1. The left photo is the MD diploma of Dr. Ghavami, received from Tehran University Medical School. In the right photo Dr. Ghavami's medical license for practicing medicine is seen.

*Corresponding author and reprints: Mohammad-Hossein Azizi MD, Associate Professor of otolaryngology, Academy of Medical Sciences of the I.R. of Iran, Tehran, Iran. Tel: +98-212-293-98-69, E-mail: azizi@ams.ac.ir 


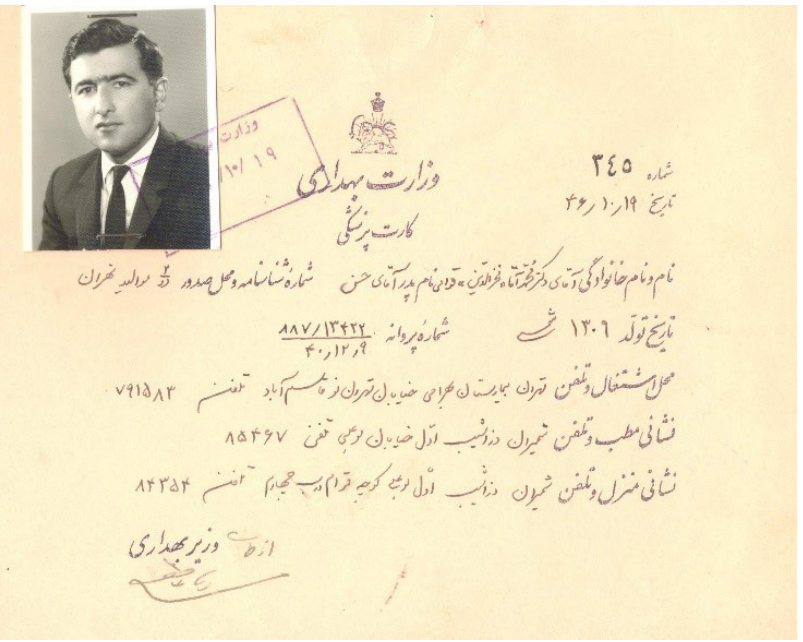

Figure 2. Dr. Ghavami's medical identification card issued in 1967.

Dr. Ghavami's role model in pediatrics was Dr. Mohammad Gharib (Figure 4). It seems that four mentors were influential in his further achievements in life and career including his father, Dr. Mojtahedi, Dr. Gharib and Dr. Mokhtarzadeh. Dr. Ghavami stated, "I liked the late Dr. Gharib very much and that was the reason why I selected the pediatrics field. My relationship with him was so close that when he was on travel, I visited his patients at his office. Dr. Gharib was a real human being. He taught me greatly. He and Dr. Mokhtarzadeh visited the patients kindly and carefully, and thus, I learned how to manage the patients. We were three pediatric residents in the Thousand-Bed or the former Pahlavi Hospital (now called Imam Khomeini Hospital). That hospital had three departments including surgery, internal medicine, and pediatrics which were headed by Dr. Sadegh Pirooz Azizi, Dr.Youssef Mir and Dr. Mohammad Gharib, respectively. I spent my medical student training, internship and pediatric residency program at that hospital. Dr. Gharib was concurrently both a teacher and a student; like a student, he always continued his medical reading and as a teacher, he taught us the consequence of his inquires."3,4

In 1964, Dr. Ghavami married Dr. Shahin Azimipour. When he was the director of the Clinic at the Bahrami's Children Hospital, Miss Shahin Azimipour was taking her internship training at the same center. After completing her internship program, she agreed to Dr. Ghavami's marriage proposal..$^{5}$

The Bahrami's Children Hospital was founded in April, 1958, with sixty beds by Mr. Mahmoud Monshibashi Bahrami. ${ }^{5}$ During the Iran-Iraq war, the Bahrami Children's Hospital was partly destroyed by an Iraqi missile strike on April 6, 1988, at about 9:15 am and sadly several people were injured and 2 innocent children and 4 hospital staffs passed away. The Hospital was reconstructed after the war, between 1992 and 1998. ${ }^{6}$ In 1988, Dr. Ghavami accepted the position of the Director of the Bahrami's Children Hospital, affiliated to the Tehran University of Medical Sciences in order to prevent the hospital from being disbanded, a duty that continued up to 1997, and then he retired in 2001.

His daughter, Dr. Bita Ghavami, a physician, said about her father' activities, "My father was a hard-working man. After his morning daily work at the hospital, he came back home, so he could be at his private office at $4 \mathrm{pm}$. Visits of his patients sometimes lasted until 2 past midnight". Besides his medical practice, she described his father's academic efforts, "He always made points that you could not find in any medical textbook. His teaching sessions at the amphitheater of the Bahrami Children's Hospital were always full of students."7 (Figure 5)

For his lifelong sincere services, Dr. Ghavami was appreciated in a ceremony in 2009 which was held by his colleagues, the former trainees and Tehran University Medical Sciences' authorities and the amphitheater of the Bahrami Children's Hospital was named after him. ${ }^{7,8}$ At the age of 81, in 2011, He was honored as one of the Shemiran's celebrities in a public meeting, held at the Qeytarieh Park in Tehran. Later, in February 2017, he was elected as a 'Best Role Model of Professional Commitment' who practiced medicine for more than six decades in a perfect ethical and professional manner and he was awarded by the Tehran Medical School Alumni Office as well as the Scientific Foundation of Dr. Bahadori (Figure 6). ${ }^{2}$

Lastly, according to his wife, Dr. Shahin Azimipour, a gynecologist, "on a snowy day in 2018, after falling down in front of the Bahrami Children's Hospital, where he worked over six decades, he suffered head trauma and in consequence, he had to stay at home for 3 years. Eventually,

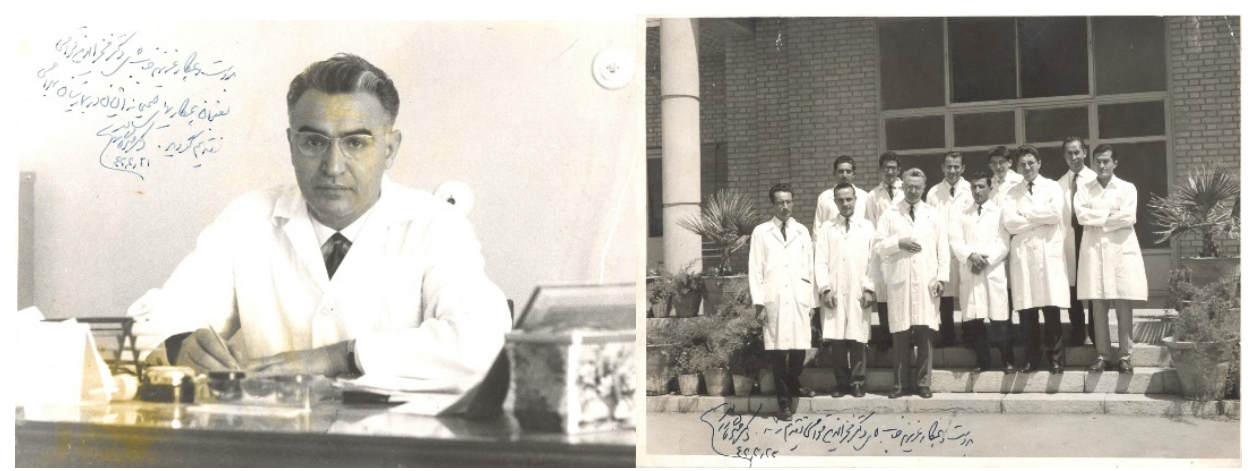

Figure 3. Left photo: Dr. Sadegh Mokhtarzadeh. In the right photo: first row, the third is Dr. Ghavami and fourth is Dr. Mokhtarzadeh who presented these photos to Dr. Ghavami in 1963. (Photos donated to Dr. Ghavami by Dr. Mokhtarzadeh and his Persian handwritings are seen on them). 


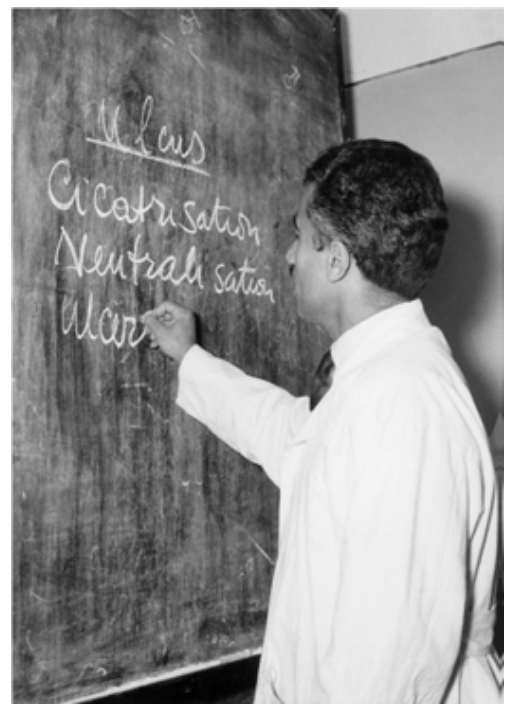

Figure 4. Professor Mohammad Gharib Delivering a Medical Lecture at the Former Pahlavi Hospital, Tehran $1965 .^{4}$

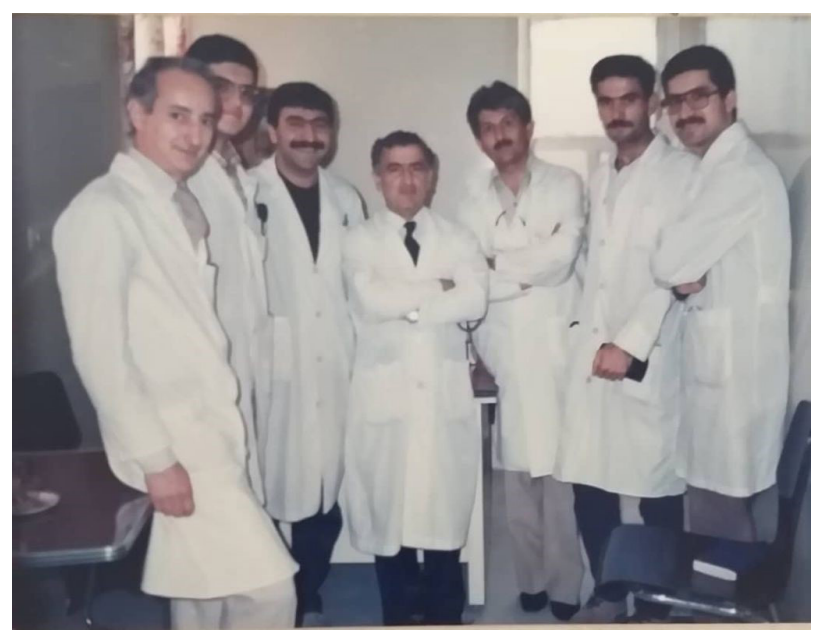

Figure 5. Dr. Ghavami among his colleagues, residents and medical students, Bahrami Children's Hospital, Tehran.

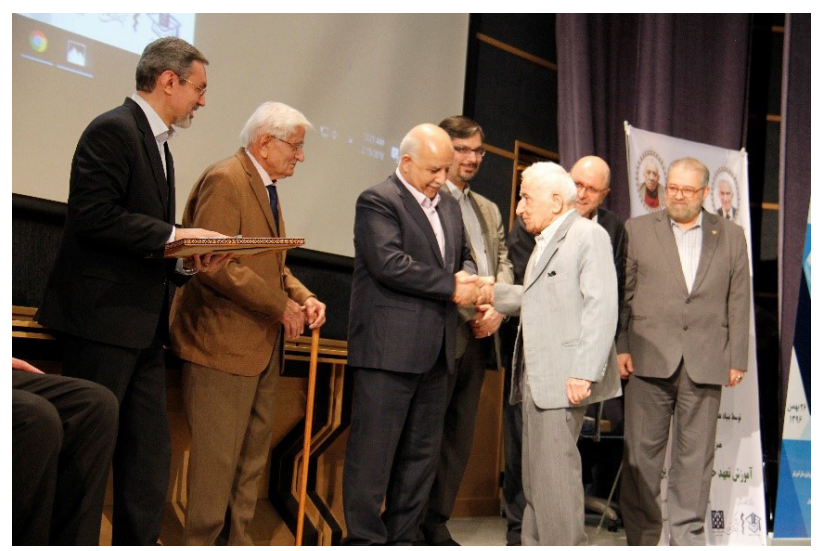

Figure 6. In February 2017, a ceremony was held and Professor Ghavami was awarded as one of the best role models of professional commitment by the Tehran Medical School Alumni Office as well as the Scientific Foundation of Dr. Bahadori. ${ }^{2}$

after three weeks of struggling with mild COVID-19, he passed away on September 1, 2021 and was buried in the Imamzadeh Ismail graveyard in Chizar, Tehran".

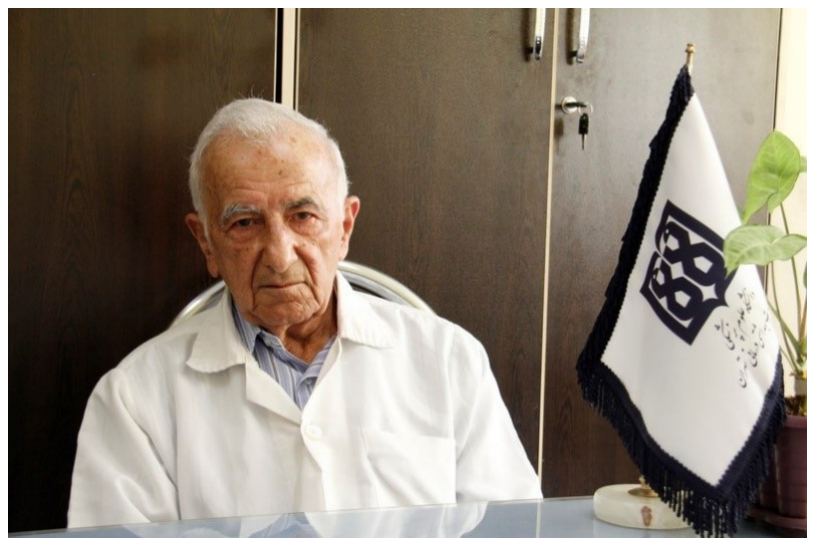

Figure 7. Professor Fakhreddin Ghavami. ${ }^{3}$

In conclusion, Professor Ghavami had an inspiring life, a loving and generous character with compassionate and moral personality. He was also a knowledgeable medical mentor. In addition, he was recognized as a philanthropist physician in Dezashib, his birth place, where he treated three generations of the patients at his simple private medical office, with lower than usual visit fees and many patients visited free of charge. Accordingly, families in Dezashib considered Professor Ghavami as a trustee and consulted him for their various matters of lives. He said in his interview, "I thank God for giving me the success of serving the community, both in my private clinic and at the hospital" (Figure 7).

\section{Authors' Contribution}

The main draft was written by the first author (MHA), then all suggestions of the second and third authors (MB and $M N$ ) were added properly. All authors confirmed the final paper.

\section{Conflict of Interest Disclosures}

The authors have no conflicts of interest.

\section{Acknowledgment}

The authors wish to thank the wife and daughter of Professor Ghavami ((Shahin Azimipour, MD, gynecologist and Tina Ghavami, pediatric dentist) for precisely reviewing the paper and their valued comments as well as providing the photos. We are also grateful to Mrs. Maryam Sepahvand, the in -charge of the Public relations of the Bahrami's Children Hospital for scanning the photos.

\section{References}

1. An interview with Dr. Fakhreddin Ghavami [in Persian]. Available frm: https://education.tums.ac.ir. Accessed October 18, 2021.

2. Dr. Fakhreddin Ghavami, a pioneering Professor of Pediatrics and Role Model of Professional Commitment. Armaghan-e Danesh Amoukhtegan [in Persian]. The special issue of the second ceremony of the selected commitment professionalism; Feb 2017.

3. Dr. Fakhreddin Ghavami, a pioneering Professor of Pediatrics and Role Model of Professional Commitment [in Persian] Available from: http://alumni.tums.ac.ir/fa/ndt/8224. Accessed October 18, 2021.

4. Bahar H, Gharib H. Mohammad Gharib M.D. His Inspiring Life and Legacy [in Persian]. $1^{\text {st }}$ ed. Washington, USA; April 2021: 30.

5. The Bahrami Children's Hospital. Rahnemai-e Daneshkadehy-e 
Pezeshki, Darousazi, Dandanpezshki va Bimarstanhy-e vabasteh [in Persian], page 210. 2nd ed. Unknown date. (First ed. Tehran University Press; January 1954).

6. Hossein Nia A. In Memory of Pioneering Physicians at the Bahrami's Children Hospital [in Persian]. Ettelat Newspaper. 21 October, 2014.
7. Mousavi M. In Memory of a Famous Dezashib Physician. [in Persian]. Available from: https://www.barkhat.news/ social/163133454165. Accessed date: 18.10.2021.

8. A Ceremony for Dr. Fakhreddin Ghavami, the Professor of Pediatrics [in Persian]. Available from: https://www.isna.ir/ news/8802-08832. Accessed October 18, 2021.

Received: September 10, 2021, Accepted: September 20, 2021, ePublished: November 1, 2021

Cite this article as: Azizi MH, Bahadori M, Naseri M. Professor Fakhreddin Ghavami (1930- 2021); a role model of professional commitment. Arch Iran Med. 2021;24(11):858-861. doi: 10.34172/aim.2021.128

(c) (1) 2021 The Author(s). This is an open-access article distributed under the terms of the Creative Commons Attribution License (http://creativecommons org/licenses/by/4.0), which permits unrestricted use, distribution, and reproduction in any medium, provided the original work is properly cited. 